\title{
Intralesional corticosteroid therapy of chalazia: a comparison with incision and curettage
}

\author{
P. M. JACOBS, V. T. THALLER, AND D. WONG \\ From Moorfields Eye Hospital, City Road, London EC1 2PD
}

SUMMARY Patients with chalazia were randomly allocated to treatment by intralesional triamcinolone injection or incision and curettage. Incision and curettage resulted in a significantly higher rate of resolution by two weeks after treatment.

Intralesional corticosteroid therapy of chalazia is not new.' The method is cheap, convenient, and free from major complications..$^{2-5}$ No special equipment is required, patient discomfort is minimal, bleeding is not a problem, and patching of the eye is not necessary.

In this study the effectiveness of a single intralesional injection of triamcinolone hexacetonide was compared with incision and curettage.

\section{Subjects and methods}

Fifty chalazia were studied from 50 patients. The two treatments were explained to each patient. Only patients who were prepared to accept either treatment, chosen at random, were recruited to the study. Six of the patients presented with more than one chalazion. In each of these only the chalazion considered by the patient to be the most severe was included in the study. Subjects under 18 years of age were excluded, as were any patients with acne rosacea. Chalazia present for less than two weeks, infected lesions, or previously treated lesion were also excluded.

The size of each chalazion was measured to the nearest millimetre, from the skin surface, across its widest dimension. Each patient was then allocated at random to receive one of two treatments.

$A$. Triamcinolone injection. Triamcinolone hexacetonide $(5 \mathrm{mg} / \mathrm{ml})$ was used. The conjunctiva was first anaesthetised with amethocaine $1 \%$ drops, and between $0.05 \mathrm{ml}$ and $0.2 \mathrm{ml}$ of the corticosteroid suspension was injected into the centre of the lesion from the conjunctival surface by means of a tuberculin syringe and a 25 gauge needle.

Correspondence to Paul Jacobs, Moorfields Eye Hospital, City Road, London EC1 2PD.
B. Incision and curettage. Amethocaine $1 \%$ drops and local infiltration with $2 \%$ lignocaine were employed. Incision and curettage were carried out through the conjunctiva with the assistance of a chalazion clamp. The eye was then padded for a few hours, and chloramphenical eye ointment was prescribed thrice daily for one week.

Patients were re-examined 14 days after the initial treatment. The size of the lesion was again measured across its widest dimension. Each patient was asked whether in his or her opinion the chalazion had completely resolved, had improved, or was the same as or worse than before treatment. Follow-up was performed by an investigator who was ignorant of which treatment the patient had received.

A chalazion was defined as cured if there was no visible lesion, no palpable swelling, and the patient stated that it had completely resolved.

\section{Results}

Twenty-three patients received intralesional triamcinolone injection (mean volume injected $0 \cdot 14$ $\mathrm{ml}$ ). All 23 patients were examined two weeks after treatment. Twenty-seven patients were treated with incision and curettage and twenty were re-examined at two weeks. The remaining seven were lost to followup. The mean age of triamcinolone-treated patients was 42.0 years and the average duration of chalazion before treatment was 14.8 weeks (range $3-52$ ). The mean age of the patients treated by incision and curettage was 36.0 years, and the average duration of chalazion 17.9 weeks (range 3-104).

The results of treatment are summarised in Tables 1 and 2 . The cure rates for each group were compared by the exact test for fourfold tables. The difference was highly significant $(p=0 \cdot 00041)$. 
Table 1 Patients' opinion of chalazion after treatment

\begin{tabular}{lrc}
\hline & Triamcinolone & $\begin{array}{l}\text { Incision and } \\
\text { curettage }\end{array}$ \\
\hline Complete resolution & 3 & 13 \\
Improved & 15 & 6 \\
Same & 4 & 1 \\
Worse & 1 & 0 \\
Total & 23 & 20 \\
\hline
\end{tabular}

Table 2 Summary of results at two weeks

\begin{tabular}{lll}
\hline & $\begin{array}{l}\text { Triamcinolone } \\
\text { injection }\end{array}$ & $\begin{array}{l}\text { Incision and } \\
\text { curettage }\end{array}$ \\
\hline $\begin{array}{l}\text { Number treated } \\
\text { Mean size pretreatment } \\
\text { (in millimetres) }\end{array}$ & 23 & 27 \\
$\begin{array}{l}\text { Number examined at two wecks } \\
\text { Mean size at two wecks }\end{array} \quad 23$ & $8 \cdot 2$ \\
$\quad$ (in millimetres) & $8 \cdot 4$ & 20 \\
$\begin{array}{l}\text { Number cured } \\
\text { Percentage curcd }\end{array}$ & $6 \cdot 7$ & $3 \cdot 4$ \\
\hline
\end{tabular}

The only complications of treatment occurred in the triamcinolone-treated group. Two patients had small subcutaneous white deposits remaining at two weeks after injection. A similar complication was described by Pizzarello et al. ${ }^{2}$

Patients from either treatment group whose chalazia were unresolved at two weeks were asked to return after a further four weeks. Of the 21 patients with triamcinolone whose chalazia were unresolved at two weeks 10 were re-examined six weeks after the initial treatment. Only one of these was cured at six weeks. The mean diameter of chalazion for these 10 patients was: before treatment, $8.5 \mathrm{~mm}$; at two weeks, $7.3 \mathrm{~mm}$; at six weeks, $5.6 \mathrm{~mm}$.

\section{Discussion}

Both groups of chalazia showed improvement after treatment. The most striking finding was the very much higher cure rate at two weeks in the group treated by incision and curettage. Seven patients in this group were lost to follow-up, but, even if we assume that none of these resolved (i.e., a cure rate of 12 out of 27 or $44.4 \%$ ), the difference would still be statistically significant $(p=0.0047)$. The proportion cured in this group is also much higher than that found by Cottrel et al. ${ }^{6}$ for spontaneous resolution. The results of intralesional triamcinolone injection in our study were disappointing. The findings in the triamcinolone-treated patients who were seen again at six weeks after treatment suggested that some resolution did occur after the first two weeks. Higher doses of corticosteroid might have been more effective, but the dose that we employed was similar to that used by others with more encouraging results. ${ }^{2-5}$ Greater success might have been achieved by employing more than one injection of triamcinolone. The main advantage, however, or intralesional steroid therapy is its convenience for both doctor and patient. If repeated injection is necessary, this advantage disappears.

We conclude that incision and curettage remains the treatment of choice for chalazion. There may be a place for corticosteroid therapy in, for example, acute chalazia or lesions near the medial canthus to avoid damage to lacrimal drainage, but this has yet to be established.

\section{References}

1 Leinfelder PJ. Depo-Medrol in treatment of acute chalazion. Am J Ophthalmol 1964; 58: 1078.

2 Pizzarello LD, Jakobiec FA, Hofeldt AJ, Podolsky MM, Silvers DN. Intralesional corticosteroid therapy of chalazia. Am J Ophthalmol 1978; 85: 818-21.

3 Dua HS, Nilawar DV. Nonsurgical therapy of chalazion. Am J Ophthalmol 1982; 94: 424-5.

4 Palva J, Pohjanpelto PEJ. Intralesional corticosteroid injection for the treatment of chalazia. Acta Ophthalmol (Kbh) 1983; 61: 933-7.

5 Castren J, Stenborg T. Corticosteroid injection of chalazia. Acta Ophthalmol (Kbh) 1983; 61: 938-42.

6 Cottrell DG, Bosanquet RC, Fawcett IM. Chalazions: the frequency of spontancous resolution. Br Med J 1983; 287: 1595. 